\title{
Rapid and sensitive detection of Nosema bombycis using loop-mediated isothermal amplification and colorimetric nanogold
}

\author{
Weijiang Dai ${ }^{\mathrm{a}}$, Jingru $\mathbf{Q i}^{\mathrm{a}}$, Hongli Chen ${ }^{\mathrm{a}}$, Zhilin Zhang ${ }^{\mathrm{a}}$, Ruisha Shang ${ }^{\mathrm{a}}$, Yiling Zhang ${ }^{\mathrm{a}, \mathrm{b}, \mathrm{c}}$, \\ Shunming Tang ${ }^{\mathrm{a}, \mathrm{b}, \mathrm{c}}$, Zhongyuan Shen ${ }^{\mathrm{a}, \mathrm{b}, \mathrm{c}, *}$ \\ a Jiangsu University of Science and Technology, Zhenjiang 212018, Jiangsu Province, China \\ b Sericultural Research Institute, Chinese Academy of Agricultural Sciences, Zhenjiang 212018, \\ Jiangsu Province, China \\ c Key Laboratory of Genetic Improvement of Silkworm and Mulberry of Agricultural Ministry, \\ Zhenjiang 212018, Jiangsu Province, China
}

*Corresponding author, e-mail: szysri@163.com

Received 24 Feb 2019

Accepted 30 Jun 2019

\begin{abstract}
Salt-induced self-aggregation of gold nanoparticles (AuNP) carrying the ssDNA probes can be prevented specifically by complementary DNA. Loop-mediated isothermal amplification (LAMP) can amplify DNA rapidly. In the present study, we established a LAMP-AuNP method for detection of the microsporidium Nosema bombycis by combining the two techniques. The DNA templates of microsporidia were extracted by FTA card. The amplified product can be visually detected via hybridization at $63^{\circ} \mathrm{C}$ for $5 \mathrm{~min}$ with a ssDNA-labelled nanogold probe, followed by salt-induced AuNP aggregation. The LAMP-AuNP assay needs approximately $65 \mathrm{~min}$. This method can detect $10 \mathrm{spores} / \mathrm{ml}$ and is specific for $N$. bombycis. When it was used to detect pebrine disease of the silkworm eggs, the maximum sample size for silkworm eggs was 700, in which only one egg was infected with N. bombycis. The new LAMP-AuNP is a simple, sensitive and specific detection assay for $N$. bombycis.
\end{abstract}

KEYWORDS: FTA card, gold nanoparticle, LAMP, microsporidia, silkworm eggs

\section{INTRODUCTION}

Microsporidia are a group of obligate intracellular eukaryotes that infect almost all of vertebrates and invertebrates ${ }^{1-3}$. Silkworm pebrine disease is a devastating disease in sericulture. N. bombycis cannot only parasitize in the silkworm larva, pupa, and moth, but can also be transmitted to the next generation through the silkworm eggs, which leads to a decline in the yield and quality of cocoons, and causes great losses in sericulture ${ }^{4}$. Because it is a kind of infectious disease and can be transmitted to the progeny through the eggs, silkworm pebrine disease is listed as the only inspection and quarantine target in silkworm eggs production.

Spot check of the female silkworm moths is the most important part of the pebrine inspection work, but its accuracy is affected by many factors, which may cause unqualified silkworm eggs to flow into the market and would make the users suffer unnecessary economic losses ${ }^{4,5}$. Many methods such as identification by naked-eyes, microscopic examination, serological and molecular biology detection techniques, were established to detect the $N$. bombycis ${ }^{6-8}$. To improve the detection of $N$. bombycis, China also has introduced the eggs testing for silkworm pebrine disease as a reserved inspection project ${ }^{4}$. However, the inspection for pebrine disease of silkworm eggs under microscopy is a time-consuming, labor-intensive work due to the huge amount of silkworm eggs. Molecular biology diagnostic methods with high specificity and sensitivity is needed urgently for silkworm pebrine disease $^{9,10}$. To apply molecular biology detection techniques for inspection of $N$. bombycis of silkworm eggs, it is necessary to establish a simple and sensitive method. Loop-mediated isothermal amplification (LAMP) was established by Japanese scholar Tsugunori Notomi, it can detect only a few copies of target nucleic acid under isothermal conditions utilizing self-recurring strand-displacement DNA synthesis initiated by specially designed primer sets $^{11}$. This technology has been widely used for the detection of pathogenic microorganisms ${ }^{12,13}$. 
LAMP products could be detected by agarose gel electrophoresis and may also be assessed indirectly by the amount of white magnesium pyrophosphate precipitate or fluorescence formed ${ }^{14,15}$.

Gold nanoparticles (AuNP) have been used widely as tools to detect target nucleic acid sequence of pathogenic microorganisms ${ }^{16,17}$. It has been reported that salt-induced self-aggregation of AuNP carrying the ssDNA probes can be prevented specifically by complementary DNA ${ }^{18}$. To date, method combining AuNP with LAMP has not been used for $N$. bombycis detection. In this study, we established a rapid, simple, efficient method for detection of $N$. bombycis by using glass beads and FTA card to extract the DNA, performing DNA amplification by LAMP and visualizing amplification products by the AuNP colorimetric assay.

\section{MATERIALS AND METHODS}

\section{Microsporidia, bacteria, fungi and virus}

The N. bombycis, Enterococcus, Beauveria bassiana, Bombyx mori Nuclear Polyhedrosis Virus (BmNPV) and B. mori Cytoplasmic Polyhedrosis Virus (Bm$\mathrm{CPV}$ ) were provided by the pathology laboratory of the Sericultural Research Institute of Chinese Academy of Agricultural Sciences.

\section{Silkworm eggs}

Silkworm eggs for microsporidian inspection which had been tested as pebrine positive under microscope were provided by the pathology laboratory of the Sericultural Research Institute of Chinese Academy of Agricultural Sciences.

\section{Extraction of microsporidian DNA}

Purified microsporidian spores or silkworm eggs were placed in a $2 \mathrm{ml}$ tube, and glass beads (Sigma Aldrich (Shanghai) Trading Co., Ltd., China) (1/2 of the volume of the tube) and $1 \mathrm{ml} \mathrm{TE}(10 \mathrm{mM}$ tris$\mathrm{HCl}$ and $1 \mathrm{mM}$ EDTA, pH 8.0) buffer were added into the tube ${ }^{4}$. The sample was crushed by a MiniBead Beater (BioSpec, USA) at $4800 \mathrm{~g}$ for $5 \mathrm{~min}$ with glass beads and buffer, and $100 \mu \mathrm{l}$ of the resulting solution of broken spores was added to the FTA card (Whatman, UK). The FTA card was dried at room temperature in dark, and a small round hole (diameter of $2 \mathrm{~mm}$ ) on the FTA card was clipped. The card pieces were washed three times with a special FTA buffer and then washed twice with TE-1 (10 mM tris- $\mathrm{HCl}$ and $0.1 \mathrm{mM}$ EDTA, $\mathrm{pH}$ 8.0) buffer. After drying at $56^{\circ} \mathrm{C}$, the FTA card pieces could be used as DNA templates for PCR and LAMP reactions.

\section{Primers and LAMP assay optimization}

LAMP primers were designed by using the PRIMER EXPLORER 4 (Eiken Chemical, Tokyo) according to the small subunit ribosomal RNA (SSU rRNA) gene of $N$. bombycis (GenBank Accession No. AY259631). The details of the primers are listed in Table 1 . For optimization of the temperature and time conditions, LAMP reactions were carried out at 60,63 , or $65^{\circ} \mathrm{C}$ for 45 or $60 \mathrm{~min}$, respectively. LAMP reactions were performed in $25 \mu \mathrm{l}$ of total reaction mixture containing $1.6 \mu \mathrm{M}$ each forward inner primer (FIP) and backward inner primer (BIP), $0.2 \mu \mathrm{M}$ each forward outer primer (F3) and backward outer primer (B3), $1.4 \mathrm{mM}$ of dNTP mix (Sangon Biotech, Shanghai, China), $6 \mathrm{mM} \mathrm{MgSO}$, $0.4 \mathrm{M}$ betaine (USB Corporation, OH, USA), 8 U Bst 2.0 WarmStart DNA polymerase (large fragment; New England Biolabs Ltd., Beijing, China), and $1 \mathrm{x}$ thermopol-supplied reaction buffer. LAMP products were analysed by $2 \%$ agarose gel electrophoresis.

\section{PCR primers and reaction conditions}

PCR primers were designed according to the SSU rRNA gene of $N$. bombycis: forward primer, $5^{\prime}$ TCCAATGGATGCTGTGAA-3'; reverse primer: $5^{\prime}$ AAGAACAGGGACTCATTCA- $3^{\prime}$. The amplification was performed using the following conditions: initial DNA denaturation at $98^{\circ} \mathrm{C}$ for $2 \mathrm{~min}, 30$ cycles of $98^{\circ} \mathrm{C}$ for $10 \mathrm{~s}, 50^{\circ} \mathrm{C}$ for $15 \mathrm{~s}$, and $72^{\circ} \mathrm{C}$ for $20 \mathrm{~s}$.

\section{Preparation of gold nanoparticles (AuNP)}

Before AuNP preparation, all glasswares were treated with chromic acid. An AuNP colloid comprised of approximately 15-nm-diameter particles was prepared ${ }^{18}$. Briefly, $100 \mathrm{ml}$ of $0.01 \% \mathrm{HAuCl}_{4}$ solution (in Milli-Q purified water) in a $500 \mathrm{ml}$ conical beaker was boiled thoroughly, and then $3.5 \mathrm{ml}$ of $1 \%$ trisodium citrate solution was added under constant stirring. After the color of the solution changed to red about $45 \mathrm{~s}$, it was boiled for another $5 \mathrm{~min}$, then the heating source was removed, and the colloidal gold solution was stirred for another $10 \mathrm{~min}$. The solution was stored in a dark bottle at $4^{\circ} \mathrm{C}$.

\section{Gold nanoparticles (AuNP) probe preparation}

A monosense ssDNA probe for the AuNP-based hybridization step was designed to the sequence spanned by the F1c-B1c region of the LAMP amplicon and labelled with a thiol group at the $5^{\prime}$ end (Table 1). The ssDNA-labelled AuNP probe was prepared by modification of previous methods ${ }^{16,17}$. 
Table 1 Primers used for loop-mediated isothermal amplification-AuNP assay for the detection of N. bombycis.

\begin{tabular}{lll}
\hline Primers & Position & Sequence $\left(5^{\prime}-3^{\prime}\right)$ \\
\hline F3 & $858-875$ & TCCAATGGATGCTGTGAA \\
B3 & $1085-1103$ & AAGAACAGGGACTCATTCA \\
FIP & $934-958 / 884-906$ & GACCTGTTTTAATCCTCTCCTTCAT-TAATTTCAACAAGATGTGAGACC \\
BIP & $982-1004 / 1042-1064$ & GTTGCACGCGCAATACAATAATA-TTTACTAGCAATTCCATGTTCAA \\
$N$. bombycis thiol probe & SH-A10/960-980 & SH-AAAAAAAAAA-GTTATGCCCTAAGATAATCTG \\
\hline
\end{tabular}

In brief, $2 \mathrm{nM}$ ( $20 \mu \mathrm{l}$ of $100 \mu \mathrm{M}$ stock) ssDNA probe was added to $5 \mathrm{ml}$ colloidal AuNP (15 nm diameter) and incubated at $50^{\circ} \mathrm{C}$ with shaking at $150 \mathrm{~g}$ for $24 \mathrm{~h}$. Then, $500 \mu \mathrm{l}$ of the buffer (100 mM Tris$\mathrm{HCl}(\mathrm{pH} 8.3), 500 \mathrm{mM} \mathrm{KCl}$ and $15 \mathrm{mM} \mathrm{MgCl}_{2}$ ) was gradually added to the mixture followed by further incubation at $50^{\circ} \mathrm{C}$ with shaking at $150 \mathrm{~g}$ for $24 \mathrm{~h}$. After centrifugation at $12000 \mathrm{~g}$ at $4{ }^{\circ} \mathrm{C}$ for $45 \mathrm{~min}$, the pellet was washed with $500 \mu \mathrm{l}$ wash buffer $(10 \mathrm{mM}$ Tris- $\mathrm{HCl}, 50 \mathrm{mM} \mathrm{KCl}$ and $1.5 \mathrm{mM}$ $\mathrm{MgCl}_{2}$ ) before resuspended in $500 \mu \mathrm{l}$ of wash buffer for storage at $4^{\circ} \mathrm{C}$.

\section{Optimization of the AuNP probe hybridization for detection of LAMP amplicons}

The hybridization for the detection of LAMP amplicons was conducted in a total volume of $15 \mu \mathrm{l}$ by mixing the LAMP amplicon solution and AuNP probe at different ratios $(7: 3-3: 7 \mu \mathrm{l})$ at $63^{\circ} \mathrm{C}$ for $5 \mathrm{~min}$. Following addition of $5 \mu \mathrm{l} 30 \mathrm{mM} \mathrm{MgSO}_{4}$ solution, the mixtures were examined visually for any color change. As the salt concentration induced aggregation, the effect of different $\mathrm{MgSO}_{4}$ concentrations on AuNP probe was further tested.

\section{Specificity of LAMP-AuNP test}

Specificity was tested using DNA extracted from $N$. bombycis, bacteria, fungi and virus. The resulting DNA products were visualized by the AuNP colorimetric assay and agarose gel electrophoresis (AGE). We also used AuNP probe to detect $0.5 \mathrm{nM}$ noncomplementary DNA (ACTGCGCGTGGCAAATGCGGA).

\section{Comparison of sensitivity between LAMP-AuNP and PCR assays}

The sensitivity of the two assays was determined using DNA templates extracted from different spore concentrations $\left(10-10^{4}\right.$ spores $/ \mathrm{ml}$ ). The resulting DNA products visualized by the AuNP colorimetric assay (analysed by naked-eyes observation) and AGE were compared.

\section{Evaluation of LAMP-AuNP assay with infected silkworm eggs}

Different numbers of uninfected silkworm eggs (99, 199, 299, 399, 499, 599, 699, 799, 899, and 999) mixed with one infected egg were immersed in 30\% $\mathrm{KOH}$ at $37^{\circ} \mathrm{C}$ for $10 \mathrm{~min}$, rinsed twice with $\mathrm{ddH}_{2} \mathrm{O}$ and once with $1 \mathrm{~mol} / 1 \mathrm{HCl}$, washed twice with $\mathrm{ddH}_{2} \mathrm{O}$ again, and sufficiently broken with a sterile tooth pick, respectively. Then $1 \mathrm{ml}$ of TE buffer was added to the mixture of eggs. The mixed eggs were then treated according to steps delineated in extraction of microsporidian DNA section to extract the DNA. The samples were analyzed using LAMPAuNP and PCR assays as described above and the results were compared.

\section{RESULTS}

\section{LAMP conditions and LAMP primer specificity}

LAMP reactions at 60,63 , and $65^{\circ} \mathrm{C}$ using $500 \mathrm{pg}$ of $N$. bombycis DNA template revealed that $63^{\circ} \mathrm{C}$ yielded the highest amounts of DNA products (Fig. 1a). For LAMP reactions performed at $63^{\circ} \mathrm{C}$ for 45 and $60 \mathrm{~min}$, DNA quantity at $60 \mathrm{~min}$ was higher (Fig. 1b). A reaction time of $60 \mathrm{~min}$ was thus selected as optimal. For primer specificity testing at these optimal conditions, reactions were performed using DNA from other important pathogens of silkworm, however, no cross-reactions displayed (Fig. 1c), indicating that the primers were highly specific to amplify $N$. bombycis.

\section{Effects of the ratios of AuNP probe to LAMP DNA product}

AuNP probe was hybridized in different ratios (7:33:7 $\mu \mathrm{l}$ ) to LAMP DNA products amplified from $N$. bombycis DNA and BmNPV DNA (negative control). Adding $5 \mu \mathrm{l}$ of $30 \mathrm{mM} \mathrm{MgSO}_{4}$ to the mixture with ratios of AuNP probe to LAMP product from 7:3-3:7 $\mu 1$ resulted in significant difference of color between positive samples (red) and negative control (blue) (Fig. 2a). And we also found that the color difference between positive and negative in the 
(a)
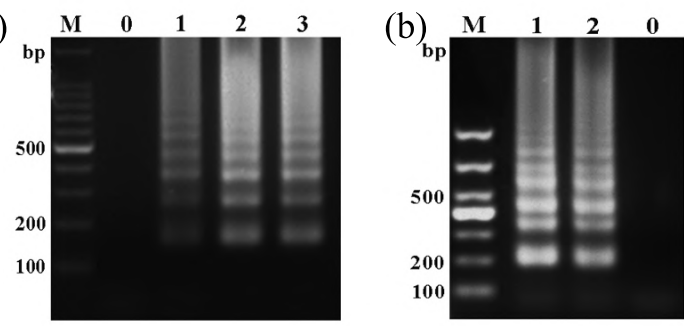

(c)

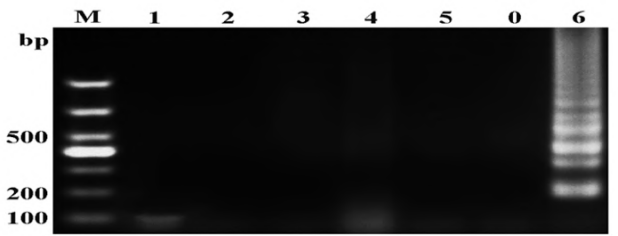

Fig. 1 Optimization of the loop-mediated isothermal amplification (LAMP) assay for the detection of $N$. bombycis. (a) Optimization of temperature for LAMP reactions using 500 pg total DNA extracted from $N$. bombycis. Lane M: 100 bp DNA ladder marker. Lane 0: negative control, lanes 1-3: LAMP amplification from reactions carried out at 60,63 , and $65^{\circ} \mathrm{C}$, respectively. (b) Optimization of LAMP reactions for various time. Lane M: 1000 bp DNA marker, lane 0: negative control, lanes 1-2: the reaction was carried out for 60 and $45 \mathrm{~min}$, respectively. (c) Evaluation of LAMP primer specificity using nucleic acid templates extracted from different pathogenic microorganism and B. mori. Lane M: 1000 bp DNA marker, lane 0: negative control, lanes 1-6: Enterococcus, B. bassiana, B. mori Nuclear Polyhedrosis virus (BmNPV), B. mori Cytoplasmic Polyhedrosis virus (BmCPV), B. mori, and N. bombycis.

group of 5:5 $\mu 1$ ratio was obvious and steady, so the 5:5 $\mu \mathrm{l}$ ratio was chosen for subsequent experiments.

\section{Effect of salt concentration}

The effect of salt concentration on aggregation was tested by addition of $5 \mu 1 \mathrm{MgSO}_{4}$ at different concentrations $(20,30$, and $40 \mathrm{mM})$. Color changes were compared between LAMP amplicons from $N$. bombycis target DNA and noncomplementary target DNA (Fig. 2b). Addition of $20 \mathrm{mM} \mathrm{MgSO}$ to mixtures containing non-target DNA did not give the change from red to blue, and addition of $30 \mathrm{mM}$ or $40 \mathrm{mM}$ $\mathrm{MgSO}_{4}$ to mixtures containing $N$. bombycis amplicons remained red or purple red, whereas addition of $30 \mathrm{mM} \mathrm{MgSO}{ }_{4}$ or $40 \mathrm{mM} \mathrm{MgSO}$ to mixtures containing non-target DNA make the color change from red to blue. Based on these data, the $30 \mathrm{mM}$ salt concentration was chosen in this study. (a)

Ratio of AuNP probe and LAMP product $(\mu \mathrm{l}: \mu \mathrm{l})$

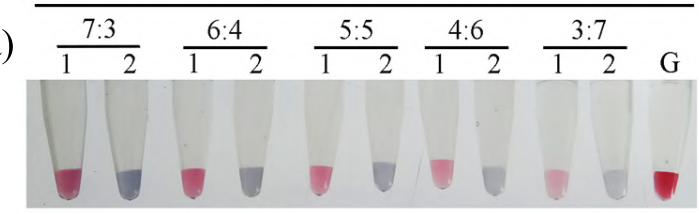

(b)

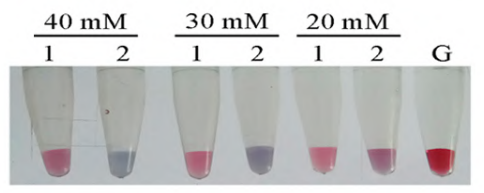

Fig. 2 Optimization of the AuNP hybridization assay. (a) Effect of ratios of AuNP probe to LAMP amplification. Tubes containing either (1) $N$. bombycis-LAMP amplification or (2) BmNPV-LAMP amplification (noncomplementary DNA) were mixed with the probe at ratios of 7:33:7 $\mu \mathrm{l}$ followed by addition of $5 \mu \mathrm{l}$ of $30 \mathrm{mM} \mathrm{MgSO}_{4}$. The positive control (G) consisted of untreated AuNP probe. (b) Effect of salt concentration. Three sets of tubes containing $5 \mu \mathrm{l}$ of (1) N. bombycis-LAMP amplification or (2) BmNPV-LAMP amplification (noncomplementary DNA) were mixed with $5 \mu \mathrm{l}$ of AuNP probe solution followed by addition of $\mathrm{MgSO}_{4}$ (5 $\mu \mathrm{l}$ fixed volume) at concentrations between 20 and $40 \mathrm{mmol} / \mathrm{l}$. The positive control (G) consisted of untreated AuNP probe.
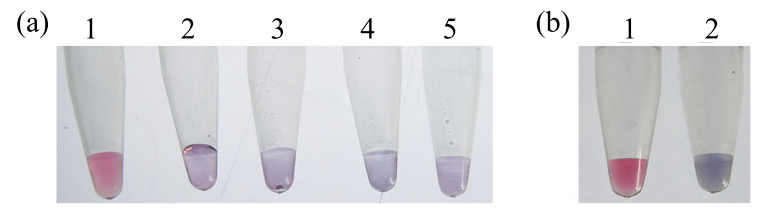

Fig. 3 Colorimetric results for the specificity of LAMPAuNP detection of $N$. bombycis. (a) LAMP-AuNP assay by naked-eyes using the DNA template extracted from different pathogenic microorganism. Lanes 1-5: N. bombycis, Enterococcus, B. bassiana, BmNPV, and BmCPV, respectively. (b) Hybridization between the AuNP probe and nucleotide sequence. Lane 1: $N$. bombycis-LAMP amplification, lane 2: $0.5 \mathrm{nM}$ noncomplementary DNA.

\section{Specificity of LAMP-AuNP detection}

AGE analysis of LAMP DNA amplified from N. bombycis, bacteria, fungi, virus is consistent with the results of LAMP-AuNP assay (Figs.1c, 3a), indicating that the LAMP-AuNP assay was specific to $N$. bombycis. Using $0.5 \mathrm{nM}$ noncomplementary DNA for AuNP hybridization assay, the color of its mixture changed from red to blue (Fig. 3b), suggesting that LAMP-AuNP assay can distinguish target DNA and noncomplementary DNA. 


\section{Comparison sensitivity between LAMP-AuNP and PCR assay}

The LAMP-AuNP method was able to detect 10 spores $/ \mathrm{ml}$, and this result was consistent with the sensitivity of LAMP followed by gel electrophoresis (Fig. 4ab). The PCR assay can detect the minimum spore concentration of 102 spores $/ \mathrm{ml}$, and the PCR amplification product of $10 \mathrm{spores} / \mathrm{ml}$ is too low to be detected easily (Fig. 4e).

\section{Detection of silkworm eggs infected with $N$. bombycis using LAMP-AuNP}

Different numbers of silkworm eggs (100, 200, 300, $400,500,600,700,800,900$, and 1000), in which only one egg is infected with $N$. bombycis, were tested by LAMP-AuNP and PCR assays, respectively. AGE analysis of LAMP DNA amplified from different samples is consistent with the results of LAMP-AuNP assay. The maximum sample size for LAMP-AuNP is 700 silkworm eggs (Fig. 4cd), while that for PCR assay is 200 silkworm eggs (Fig. $4 \mathrm{f}$ ).

\section{DISCUSSION}

LAMP and PCR have been widely used in the detection of microsporidia ${ }^{4,17,19}$. However, it is difficult to apply PCR or LAMP techniques for inspection of the silkworm pebrine disease of silkworm eggs. According to previous studies ${ }^{19,20}$, Liu et al found that there may be some inhibitory factor in silkworm eggs that interfered with PCR amplification of $N$. bombycis DNA. In this study, we used glass beads and FTA card to extract DNA, with which proteins and other impurities in the samples can be removed by simple operations on FTA card ${ }^{4,21}$. The recovery of genomic DNA is an important factor affecting the sensitivity of $N$. bombycis detection. The DNA recovery efficiency of the conventional method ${ }^{22}$ to extract genomic DNA from microsporidia is too low. In contrast, treatment with acid-washed glass beads can extract most of microsporidian nucleic acids because the broken rate of spores can reach $90 \%{ }^{23}$. In this study, the maximum sample size of LAMP-AuNP is 700 silkworm eggs, in which only one egg was infected with $N$. bombycis, while that of PCR assay is 200 silkworm eggs.

Using agarose gel electrophoresis to visualize the amplicons from LAMP is not convenient for workers in silkworm eggs producing farm. Due to their ability to interact with disulfide modified DNA and the unique optical properties, AuNP show great promise for use in rapid field diagnosis methods ${ }^{17,24}$. Because LAMP DNA products carry abundant negative charges on their phosphate backbones, interaction with the AuNP probe particles would increase the negative charges of the amplicon-probe complexes, thus enhancing electrostatic and steric repulsion between amplicons ${ }^{16}$. LAMP and AuNP hybridization assay have been used in detection of shrimp yellow head virus and Enterocytozoon hepatopenaei ${ }^{16,17}$. However, whether the LAMP-AuNP method could be used to detect $N$. bombycis in silkworm eggs, each test condition should be optimized separately.

In this study, $63^{\circ} \mathrm{C}$ for $60 \mathrm{~min}$ was found as optimal for LAMP with high sensitivity and specificity. By using Bst 2.0 WarmStart DNA polymerase, the reaction of LAMP could be performed at room temperature which makes the LAMP assay more convenient. For AuNP hybridization step, we found that the ratio between LAMP amplicons and AuNP probe was essential for valid detection of target DNA. Too little or too much of LAMP amplicons or AuNP probe could result in a false negative result so the optimal ratio was set at 5:5 $\mu 1$ since it provided reproducible color differences between positive and negative test results (Fig. 2a). Salt-induced selfaggregation of AuNP carrying ssDNA probes can be prevented specifically by complementary DNA ${ }^{18}$. However, it was found that in the presence of LAMP amplicons, a high salt concentration could yet induce color change of AuNP probe, resulting in a false negative result, suggesting that the optimal salt concentration was critical to LAMP-AuNP method ${ }^{17}$. In this study, the optimal salt concentration was $30 \mathrm{mmol} / 1 \mathrm{MgSO}_{4}$, because in the presence of LAMP amplicons, it was insufficient to induce AuNP selfaggregation (Fig. 2b).

Noncomplementary DNA or no DNA were used as templates (negative control) to confirm that the specific hybridization between the AuNP probe and its target DNA prevented its salt-induced aggregation (Figs. 1c, 2b, 3a). In this study, it is also found that large amounts of noncomplementary DNA could not prevent the salt-induced aggregation of AuNP probes (Fig. 3b).

In conclusion, AuNP have unique optical properties that make them suitable for the design of labelled AuNP probes. Salt-induced self-aggregation of gold nanoparticles carrying unisense ssDNA probes can be prevented specifically by complementary DNA. They offer the advantages of low cost and visual detection over most conventional methods of detection such as those used in fluorescence or radioactivity-based assays. LAMP can amplify DNA rapidly. The combined LAMP-AuNP method re- 
(a)

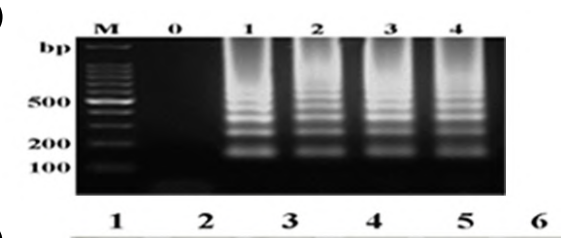

(b)

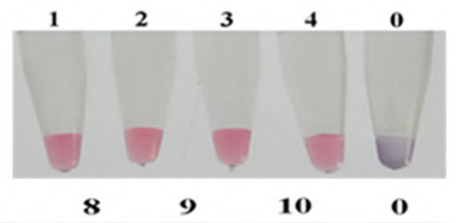

(c)

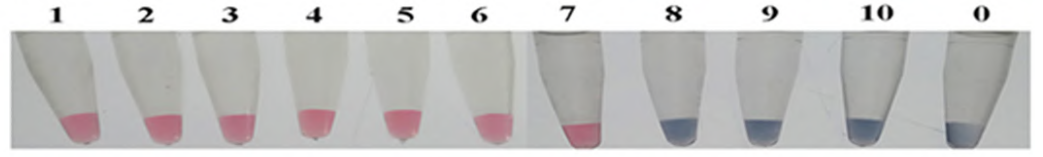

(d)

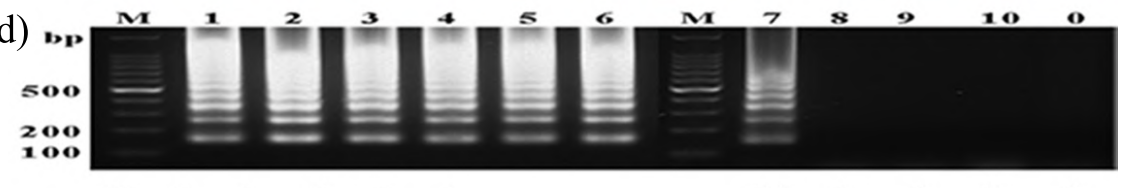

(e)

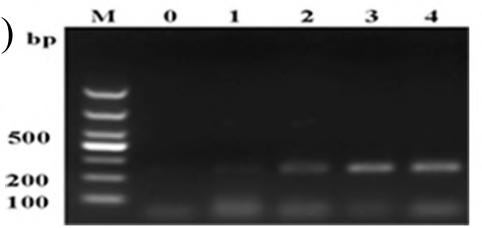

(f)

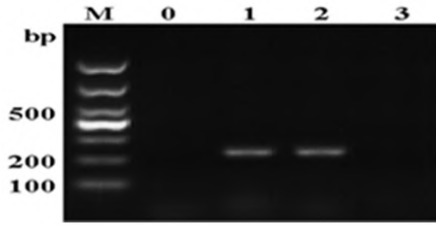

Fig. 4 Detection of $N$. bombycis using LAMP-AuNP or PCR. (a) The sensitivity of LAMP for the detection of $N$. bombycis spores/ml. Lane M: 100 bp DNA ladder marker, lane 0: negative control, lanes 1-4: the DNA template extracted from 104, 103, 102, and 10 spores/ml, respectively. (b) LAMP-AuNP assay by naked-eyes using the same template sets as in (a). lane 0: negative control, lanes 1-4: 104, 103, 102, and 10 spores/ml, respectively. (c) LAMP-AuNP results of LAMP reactions performed using the DNA templates extracted from different numbers of silkworm eggs. Lane 0: negative control, lanes 1-10: different numbers of silkworm eggs, 100, 200, 300, 400, 500, 600, 700, 800, 900, 1000, respectively. (d) AGE results of LAMP reactions performed using the same template sets as in (c). Lane 0: negative control, lanes 1-10: different numbers of silkworm eggs, 100, 200, 300, 400, 500, 600, 700, 800, 900, 1000, respectively. (e) The sensitivity of PCR for the detection of $N$. bombycis spores/ml. Lane M: 1000 bp DNA marker, lane 0: negative control, lanes 1-4: the DNA template extracted from 101, 102, 103, and 104 spores/ml, respectively. (f) The sensitivity of PCR for the detection of different numbers of silkworm eggs. Lane M: 1000 bp DNA marker, lane 0: negative control, lanes 1-3: different numbers of silkworm eggs, 100, 200, and 300, respectively.

quired 60 min for LAMP and 5 min for hybridization of LAMP products to an AuNP-labelled ssDNA probe followed by salt induced probe-particle aggregation to visualize color development. Such method employs simple, inexpensive equipment and involves simple steps, making it applicable for the detection of $N$. bombycis in small laboratories. More importantly, it serves as a model platform that could be adapted easily to detect other microsporidia using simple equipment.

Acknowledgements: This work was supported by the earmarked fund for the China Agriculture Research System and the National Natural Science Foundation of China (Grant No. 31372376). We are also grateful to all who provided the means for us to access free software, which we have used and cited in this article. We would also like to thank all partners and laboratory staff for kindly help and criticism. Weijiang Dai and Jingru Qi are co-first authors.

\section{REFERENCES}

1. Canning EU, Lom J, Dykova I (1986) The Microsporidia of Vertebrates, Academic Press, London, UK.

2. Weber R, Bryan RT, Schwartz DA, Owen RL (1994) Human microsporidial infections. Clin Microbiol Rev 7, 426-461.

3. Wittner M, Weiss LM (1999) Structure of the microsporidia. In: Vávra J, Larsson $\mathrm{R}$ (eds) The Microsporidia and Microsporidiosis, ASM Press, DC, USA, pp 7-84.

4. Yan W, Shen ZY, Tang XD, Xu L, Li QL, Yue YJ, Xiao SY, Fu XL (2014) Detection of Nosema bombycis by FTA cards and loop-mediated isothermal amplification (LAMP). Curr Microbiol 69, 532-540.

5. Dai WJ, Chen G, Peng XR, Li XL, Ma L, Tang XD, Xu L, Shen ZY (2017) Staining and discrimination of Nosema bombycis spores with fluorescent brightener 28 and propidium iodide. Sci Sericulture 43, 62-67. 
6. Kokoskin E, Gyorkos TW, Camus A, Cedilotte L, Purtill T, Ward B (1994) Modified technique for efficient detection of microsporidia. J Clin Microbiol 32, 1074-1075.

7. Lee SH, Joung M, Yoon S, Choi K, Park WY, Yu JR (2010) Multiplex pcr detection of waterborne intestinal protozoa: Microsporidia, cyclospora, and cryptosporidium. Korean J Parasitol 48, 297-301.

8. Stine SW, Vladich FD, Pepper IL, Gerba CP (2005) Development of a method for the concentration and recovery of microsporidia from tap water. $J$ Environ Sci Health 40, 913-925.

9. Sanders JL, Kent ML (2011) Development of a sensitive assay for the detection of Pseudoloma neurophilia in laboratory populations of the zebrafish Danio rerio. Dis Aquat Org 96, 145-156.

10. Taniuchi M, Verweij JJ, Sethabutr O, Bodhidatta L, Garcia L, Maro A, Kumburu H, Gratz J, et al (2011) Multiplex polymerase chain reaction method to detect Cyclospora, Cystoisospora, and Microsporidia in stool samples. Diagn Microbiol Infect Dis 71, 386-390.

11. Tsugunori N, Hiroto O, Harumi M, Testu H (2000) Loop-mediated isothermal amplification of DNA. $\mathrm{Nu}$ cleic Acids Res 28, e63.

12. Techathuvanan C, Draughon FA, D'Souza DH (2010) Loop-mediated isothermal amplification (LAMP) for the rapid and sensitive detection of Salmonella typhimurium from pork. $J$ Food Sci 75, M165-M172.

13. Zhang FY, Shi YH, Jiang KJ, Xu ZL, Ma LB (2012) Sensitive and rapid detection of two toxic microalgae Alexandrium by loop-mediated isothermal amplification. Acta Oceanol Sin 31, 139-146.

14. Mori $Y$, Nagamine $K$, NorihiroTomita, Notomi $T$ (2001) Detection of loop-mediated isothermal amplification reaction by turbidity derived from magnesium pyrophosphate formation. Biochem Biophys Res Commun 289, 150-154.

15. Soliman H, El-Matbouli M (2006) Reverse transcription loop-mediated isothermal amplification (RT-
LAMP) for rapid detection of viral hemorrhagic septicaemia virus (VHS). Vet Microbiol 114, 205-213.

16. Jaroenram W, Arunrut N, Kiatpathomchai W (2012) Rapid and sensitive detection of shrimp yellow head virus using loop-mediated isothermal amplification and a colorogenic nanogold hybridization probe. $J$ Virol Methods 186, 36-42.

17. Suebsing R, Prombun P, Srisala J, Kiatpathomchai W (2013) Loop-mediated isothermal amplification combined with colorimetric nanogold for detection of the microsporidian Enterocytozoon hepatopenaei in penaeid shrimp. J Appl Microbiol 114, 1254-1263.

18. Song JZ, Li ZP, Cheng YQ, Liu CH (2010) Selfaggregation of oligonucleotide-functionalized gold nanoparticles and its applications for highly sensitive detection of DNA. Chem Commun 46, 5548-5550.

19. Liu JP, Cao Y, Smith JE, Xu XY (2004) Studies on the application of PCR molecular diagnosis to silkworms with simulated pebrine disease. Sci Agric Sin 37, 1925-1931.

20. Liu JP, Cheng W, Yan YW, Wei JY, Yang JL (2015) Detection of pebrine disease in Bombyx mori eggs with the loop-mediated isothermal amplification (LAMP) method based on EB1 gene. Acta Entomologica Sinica 58, 846-855.

21. Keeler SP, Ferro PJ, Brown JD, Fang XW, El-Attrache J, Poulson R, Jackwood MW, Stallknecht DE (2012) Use of FTA sampling cards for molecular detection of avian influenza virus in wild birds. Avian Dis 56, 200-207.

22. Pan MH, Wan YJ, Lu C (2001) Studies on the methods for preparing DNA of different species of microsporidia. J Southwest Agric Univ 23, 111-112.

23. Cai SF, He XY, He XK, Qiu HH, Li GC, He YQ, Lu XM (2011) A protocol for fast and efficient preparation of genomic DNA and total proteins of Nosema bombycis. Sci Sericulture 37, 1019-1024.

24. Wang ZX, Ma LN (2009) Gold nanoparticle probes. Coord Chem Rev 253, 1607-1618. 